\title{
Dynamic Behaviour of a High-Strength Structural Steel at Low Temperatures
}

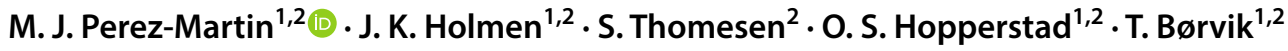

Received: 5 April 2019 / Accepted: 12 June 2019 / Published online: 24 June 2019

(c) The Author(s) 2019, corrected publication 2019

\begin{abstract}
The main objective of this experimental study is to determine the effect of low temperatures on the mechanical behaviour of Strenx 960 Plus high-strength structural steel at different strain rates and stress triaxialities. For this purpose, a comprehensive experimental campaign was designed to characterise the material at a wide range of temperatures and loading rates. The stress triaxiality was varied by testing specimens with different geometry. First, to determine the ductile-to-brittle transition temperature, instrumented Charpy V-notch impact tests were carried out at a range of temperatures from $+20^{\circ} \mathrm{C}$ down to $-90{ }^{\circ} \mathrm{C}$. The impact energy dropped gradually with decreasing temperature, but a clear transition temperature could not be identified. A fractography study exhibited a clear dimple structure, revealing predominantly ductile fracture at all temperatures. Then, uniaxial tension tests on smooth and pre-notched axisymmetric specimens under both quasi-static and dynamic loading rates were carried out at room temperature and low temperatures. These tests were conducted to characterise the rate-dependence of the stress-strain behaviour and the failure strain. The results revealed that under quasi-static conditions the flow stress increased with decreasing temperature, while the failure strain was nearly independent of the temperature. Dynamic tensile tests using the same specimen geometries were conducted in a split Hopkinson tension bar at $+20{ }^{\circ} \mathrm{C}$ and $-40{ }^{\circ} \mathrm{C}$. The material exhibited a positive strain rate sensitivity at all investigated temperatures. This experimental study reveals that the Strenx 960 Plus steel retains its ductility at temperatures as low as $-40{ }^{\circ} \mathrm{C}$. Brittle failure could not be observed even with combined high strain rate, high stress triaxiality and low temperature.
\end{abstract}

Keywords High-strength structural steel $\cdot$ Low temperature $\cdot$ High strain rate $\cdot$ High stress triaxiality $\cdot$ Ductile failure

\section{Introduction}

The amount of human activity in the Arctic region is increasing. Average Arctic winter temperatures can be as low as $-40{ }^{\circ} \mathrm{C}$, which means that Arctic structures are installed and operated at extreme temperatures and sometimes subjected to severe loading conditions. At high temperatures, steels are generally ductile. As the ambient temperature decreases, many steels become vulnerable to brittle fracture and may not be suitable for cold climate applications. Consequently,

M. J. Perez-Martin

mariajesus.perez@ntnu.no

1 Centre for Advanced Structural Analysis (CASA), Norwegian University of Science and Technology (NTNU), 7491 Trondheim, Norway

2 Structural Impact Laboratory (SIMLab), Department of Structural Engineering, NTNU, 7491 Trondheim, Norway there has been a number of studies on structural steels exposed to Arctic environments in recent years [1-8].

Ductile fracture in metals is characterised by void nucleation, growth and coalescence. Failure is a result of the voids growing to a critical size and the development of a local plastic instability. Brittle fracture is characterised by an abrupt and unexpected initiation and propagation of fracture along a particular crystallographic plane. Cleavage is a typical brittle failure, but it might also be preceded by largescale plastic flow and ductile crack growth. Dieter [9] stated that there are three basic factors contributing to cleavage: a triaxial stress state, low temperature and high strain rate. According to Anderson [10], cleavage is most likely to occur when the plastic flow is restricted.

In general, face-centred cubic (FCC) metals, like aluminium, are not susceptible to cleavage due to the large amount of slip systems at all temperatures. On the other hand, bodycentred cubic (BCC) metals, like steel, have few active slip systems when the temperature becomes sufficiently low and 
may therefore fail by cleavage. The fracture mechanism of BCC metals may change radically from ductile to brittle at a small sub-zero temperature range. This is called the ductileto-brittle transition temperature (DBTT), or the transition temperature, which is affected by the chemical composition and the microstructure. According to Dieter [9], the best combination of strength and impact resistance in steel is given by a tempered martensitic structure. In practical applications and for design purposes particularly in Arctic environments, it is important to be aware of the potential transition from ductile to brittle behaviour.

A widely used method to determine the DBTT is the Charpy V-notch impact test [11], in which a heavy pendulum strikes a notched specimen to fracture. Tests are conducted over a wide temperature range, and the energy absorption is plotted as a function of temperature.

The effect of elevated temperatures on the mechanical behaviour of metals is well known in both quasi-static and dynamic conditions $[12,13]$. In general, the strength of metallic materials decreases, and the fracture strain increases with increasing temperature. However, the behaviour of such materials at low temperatures has not been extensively studied, at least not in an impact engineering context. In a recent study by Tu et al. [14], a structural steel exhibited increased strength without losing ductility at temperatures as low as $-60{ }^{\circ} \mathrm{C}$. However, this investigation was conducted under quasi-static loading conditions and the effect of high strain rates at low temperatures was not studied. Similar results were found by Xie et al. [7] on the mechanical properties of high-strength steel wires. In that study, the ultimate strength and failure strain of the material increased as the temperature dropped from $+20^{\circ} \mathrm{C}$ down to $-100^{\circ} \mathrm{C}$, while brittle fracture was observed at temperatures below $-100{ }^{\circ} \mathrm{C}$.

The current study presents material tests using several different specimens and strain rates to investigate how a commercial high-strength steel behaves at sub-zero temperatures relevant for Arctic applications. All the results are compared to corresponding tests at room temperature. Special emphasis is put on the fracture behaviour.

\section{Material}

\section{Material Description}

The material used in the current study is the hot-rolled, quenched and tempered strip steel Strenx 960 Plus which was produced and provided by Swedish Steel AB (SSAB). It is a high-strength martensitic steel typically employed for demanding load-bearing structural applications, where the number indicates that the material has a minimum yield strength of $960 \mathrm{MPa}$. The chemical composition, both from a ladle analysis and the certificate, as well as nominal mechanical properties of the Strenx 960 Plus provided by the supplier, are summarised in Table 1. According to the material certificate, the absorbed impact energy in a Charpy test is at least $27 \mathrm{~J}$ at $-40{ }^{\circ} \mathrm{C}$.

\section{Specimen Geometries}

The experimental program included the following tests:

- Smooth and pre-notched tensile specimens subjected to quasi-static and dynamic loading rates at room and low temperatures.

- Charpy V-notch impact tests at room and low temperatures.

Smooth round bars and axisymmetric notched tensile specimens were machined from an $8 \mathrm{~mm}$ thick Strenx 960 Plus steel plate. The geometries of the smooth and pre-notched specimens with different notch-root radii are shown in Fig. 1a-c. To study the anisotropy of the material, the smooth specimens were extracted from three different orientations with respect to the rolling direction of the plate: $0^{\circ}, 45^{\circ}$ and $90^{\circ}$, with $0^{\circ}$ being the rolling direction. The pre-notched specimens, with radius $R=2.0 \mathrm{~mm}$ (R2.0) and $R=0.8 \mathrm{~mm}(\mathrm{R} 0.8)$, were only extracted from

Table 1 Chemical composition and mechanical properties of Strenx 960 Plus steel

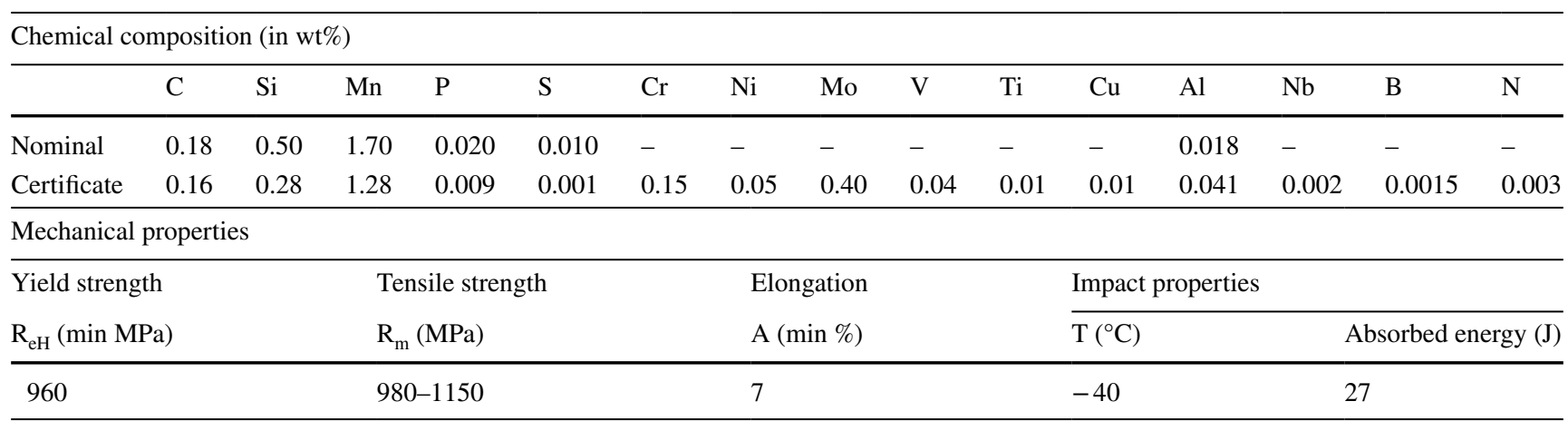


Fig. 1 Geometries of the a smooth and pre-notched tension specimens with radius, $\mathbf{b}$ $\mathrm{R}=2.0 \mathrm{~mm}$ and $\mathbf{c} \mathrm{R}=0.8 \mathrm{~mm}$, and $\mathbf{d}$ the Charpy V-notch specimen (a)

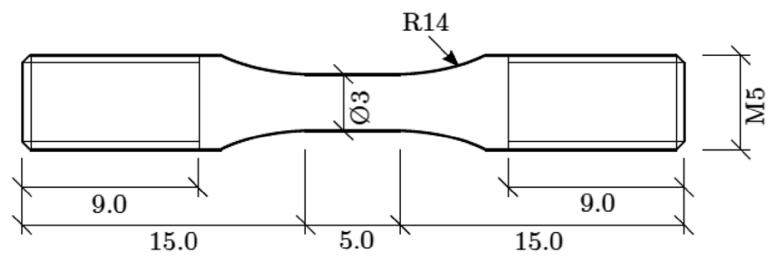

(b)

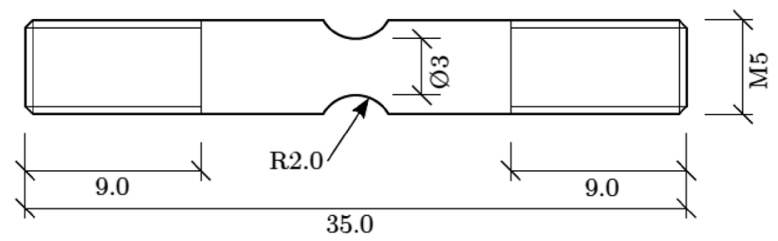

(c)
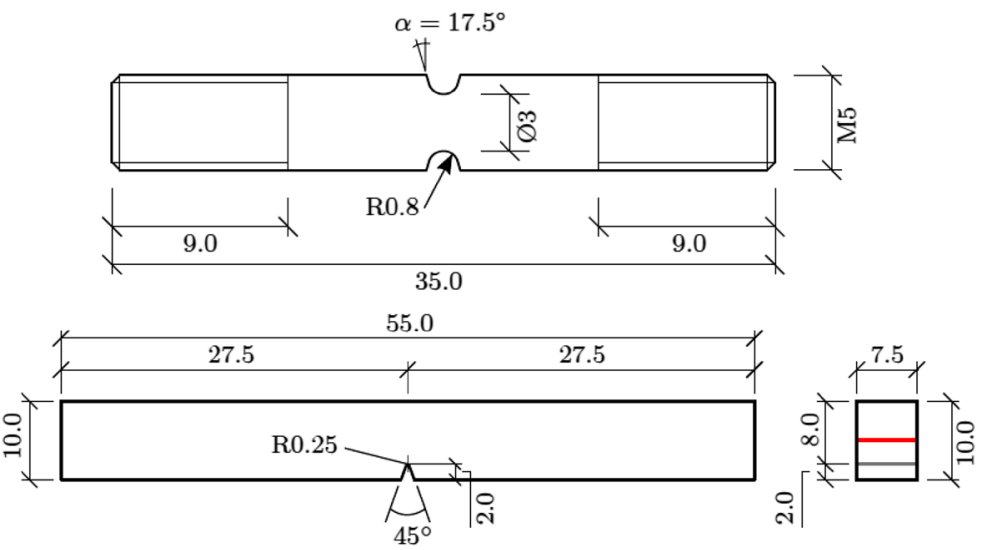

the rolling direction. Before testing, the minimum crosssection diameter of each specimen was measured with a laser gauge.

The geometry of the Charpy V-notch specimens is shown in Fig. 1d. The red line on the cross-section indicates the thickness direction of the $8 \mathrm{~mm}$ thick steel plate. The substandard geometry of the specimens was in accordance with the relevant standards [15].

\section{Experimental Procedures}

A comprehensive experimental campaign was designed to characterise the Strenx 960 Plus steel at a wide range of temperatures and loading rates. First, instrumented Charpy V-notch impact tests were conducted in an attempt to determine the ductile-to-brittle transition temperature. Then, to characterise the rate-dependence of the stress-strain behaviour and the failure strain, experiments on smooth and pre-notched tension specimens were carried out under both quasi-static and dynamic loading rates at room and low temperatures. In general, two or three repetitions were conducted for each specimen geometry and type of test. An exception is the dynamic tensile tests at room temperature on pre-notched specimens with radius R2.0 where only one test was successful.

\section{Charpy V-Notch Tests}

Charpy V-notch tests were carried out according to the ISO 148-1:2016 standard using an inverse setup (see Fig. 2) [16]. In an inverse setup, the specimen is attached to a $21 \mathrm{~kg}$ pendulum with an $800 \mathrm{~mm}$ long arm that impacts what is usually known as the striker. Before testing, the specimens were cooled down in an alcohol bath to the desired test temperatures of $+20^{\circ} \mathrm{C},-20{ }^{\circ} \mathrm{C},-40{ }^{\circ} \mathrm{C},-60{ }^{\circ} \mathrm{C},-75^{\circ} \mathrm{C}$ or $-90{ }^{\circ} \mathrm{C}$ for at least $10 \mathrm{~min}$. Then, each specimen was rapidly transferred to the impact position and impacted by the striker, the elapsed time being not more than $5 \mathrm{~s}$.

\section{Quasi-Static Tensile Tests}

The quasi-static tensile tests were conducted in a Zwick Roell Z030 electromechanical testing machine equipped with a $30 \mathrm{kN}$ load cell. The crosshead velocity of the test machine was specified to $0.15 \mathrm{~mm} / \mathrm{min}$, giving an initial strain rate in the smooth specimens of $5 \times 10^{-4} \mathrm{~s}^{-1}$. This strain rate corresponds to quasi-static conditions, even though the strain rate will increase as the specimen deforms. The tests were recorded with a digital camera configured to achieve $3 \mathrm{fps}$ with a resolution of $2448 \times 2048$ pixels. A 2 -plane mirror system allowed recording the specimen on two orthogonal planes, using 

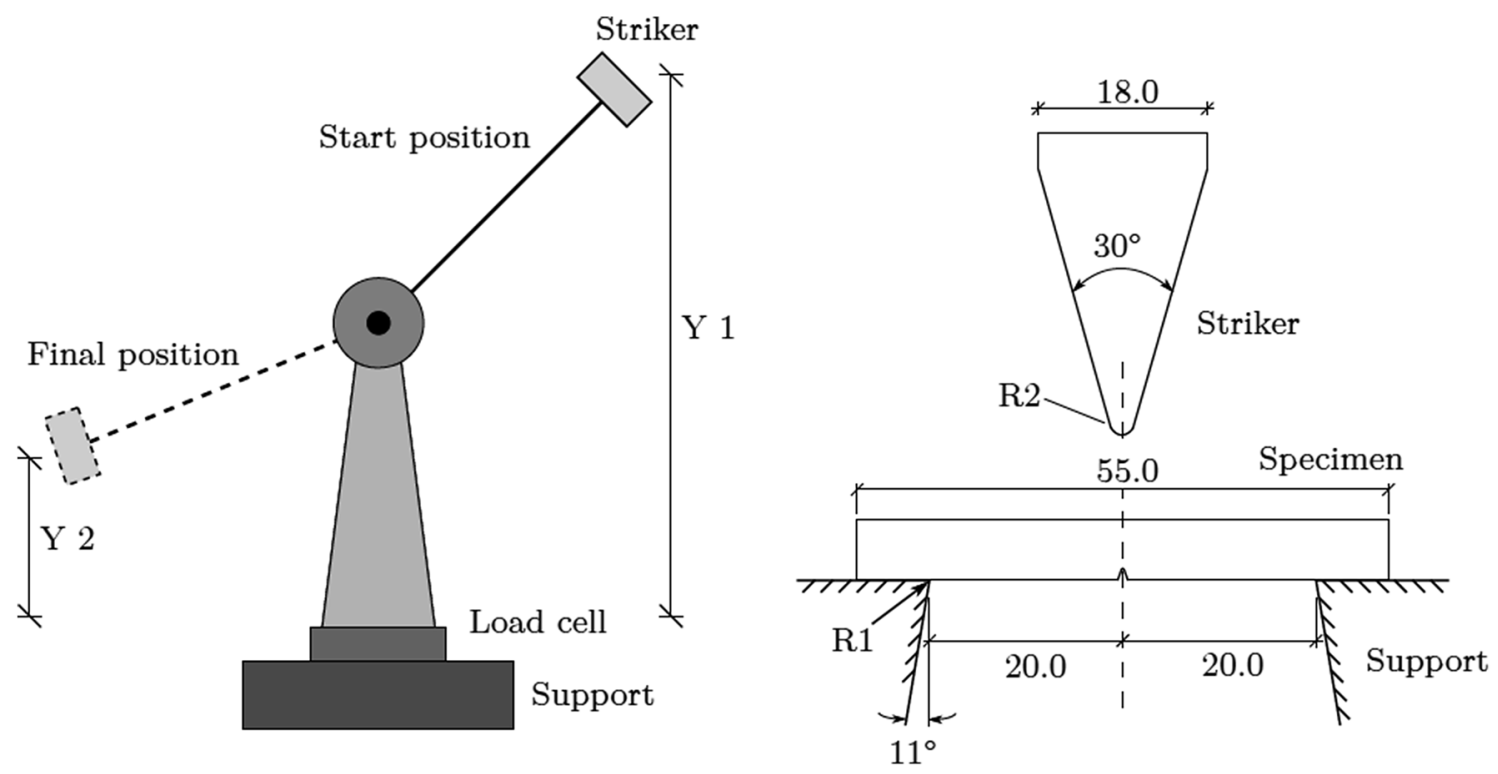

Fig. 2 Scheme of the pendulum device and the inverse set-up used for the Charpy V-notch impact tests

a LED light system to improve the grey-scale gradient between the specimen and the background. An optical edge-tracing technique $[17,18]$, implemented in the software eCorr [19], was used to monitor the minimum cross-section diameter of the specimen in two perpendicular directions (see Fig. 3a). With this technique, the gradient in grey-scale value of the specimen towards the background is used to define the edge and subsequently the minimum diameter of the specimen during loading. The edge-tracing technique was validated against DIC in [17], showing good agreement.
To study the in-plane anisotropy of the material, smooth tension specimens extracted at $0^{\circ}, 45^{\circ}$ and $90^{\circ}$ with respect to the rolling direction of the steel plate were tested at room temperature. Tensile tests of smooth and pre-notched ( $R=2.0 \mathrm{~mm}$ and $R=0.8 \mathrm{~mm}$ ) specimens extracted from the rolling direction were performed at $+20{ }^{\circ} \mathrm{C}$ and $-40{ }^{\circ} \mathrm{C}$. The tests at low temperature were conducted in a temperature chamber where the specimens were cooled down using liquid nitrogen. The chamber was equipped with a window through which the test specimen could be recorded (see Fig. 3b). After having reached the desired level, the

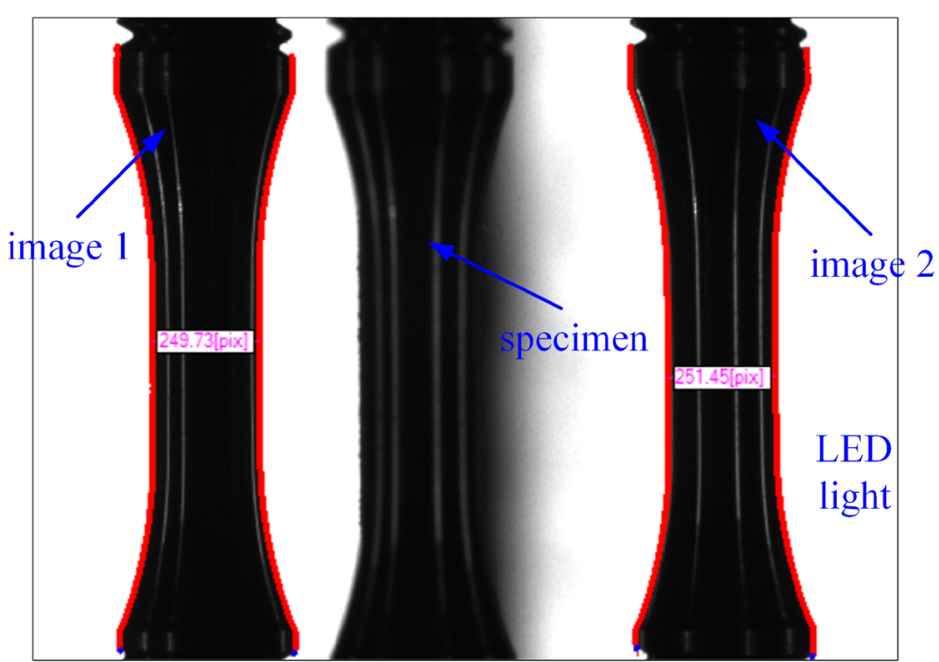

(a)

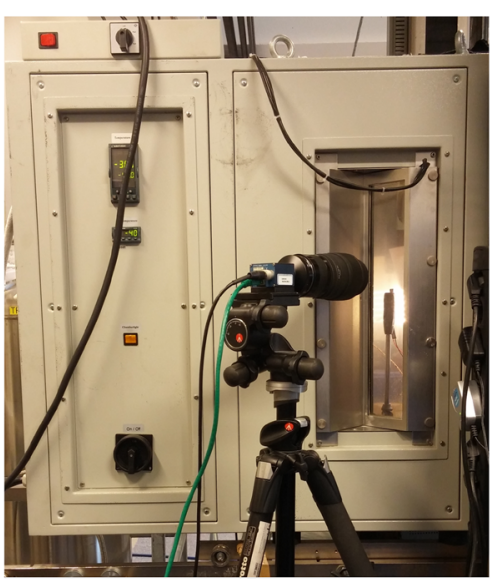

(b)

Fig. 3 a Illustration of the edge tracing technique used to monitor the minimum cross-section diameter of the specimen in two perpendicular directions. b Environmental chamber used for the low temperature tests in quasi-static regime 
temperature was held constant for at least $20 \mathrm{~min}$ to ensure no temperature gradients throughout the specimen. This was done by flushing liquid nitrogen into the chamber in a controlled way based on thermocouple measurements (see also "Dynamic Tensile Tests" section). Three thermocouples were installed inside the chamber. Two of them were spotwelded to the machine grips, while the third was located close to the centre where the specimen was held. In this way, they allowed to control the amount of liquid nitrogen flushed into the chamber to keep a constant temperature for a long time.

\section{Dynamic Tensile Tests}

Dynamic tensile tests using the same specimen geometries as in the quasi-static tests were conducted in a split Hopkinson tension bar (SHTB) at $+20{ }^{\circ} \mathrm{C}$ and $-40{ }^{\circ} \mathrm{C}$. The experimental set-up [20], schematically illustrated in Fig. 4a, was composed of an input bar (AC) and an output bar (DE), both made of steel quality Tibnor 52SiCrNi5. A friction locking mechanism (B), which clamped the input bar, allowed the stress wave to be generated. The specimen was mounted between $\mathrm{C}$ and $\mathrm{D}$. The SHTB was equipped with strain gauges at each of the positions (1), (2) and (3). Strain gauges (2) and (3) were used to determine the stress in the specimen, while gauge (1) was used to monitor the tension force $N_{0}$ used to strain the input bar. Using the signals from the strain gauge measurements, the nominal stress, nominal strain and nominal strain rate in the sample can be obtained based on one-dimensional stress wave theory (see [20] for details).
In these experiments, the force was obtained based on the transmitted stress wave, while the current cross-section diameter of each specimen was monitored using a Phantom V1610 high-speed camera and edge tracing. The camera was set up to record $240,000 \mathrm{fps}$, leading to a time increment of $4.17 \mu$ s between consecutive images, and with a resolution of $256 \times 208$ pixels. In order to perform the tests at low temperature of $-40{ }^{\circ} \mathrm{C}$, the specimen was located in a purpose-built temperature chamber made of polycarbonate to ensure visibility while being cooled down with liquid nitrogen flushed into the chamber (see Fig. 4b, c). To avoid condensation on the surface of the specimen, they were carefully cleaned with isopropyl alcohol before the tests. Three thermocouples were utilised to measure and control the sub-zero temperature: two of them were spot-welded to the bars near the specimen, while the third thermocouple was placed freely inside the chamber. It should be noted that there was only one successful test of the dynamic tensile test at $-40{ }^{\circ} \mathrm{C}$ on the pre-notched specimen R2.0.

\section{Experimental Results}

\section{Charpy V-Notch Tests}

The absorbed energy in the Charpy $\mathrm{V}$-notch tests as a function of temperature, from $+20{ }^{\circ} \mathrm{C}$ down to $-90{ }^{\circ} \mathrm{C}$, is shown in Fig. 5a. Note that the measured absorbed energy at $-40{ }^{\circ} \mathrm{C}$ is significantly higher than the minimum value given by the material certificate (see Table 1 ). The results

(a)
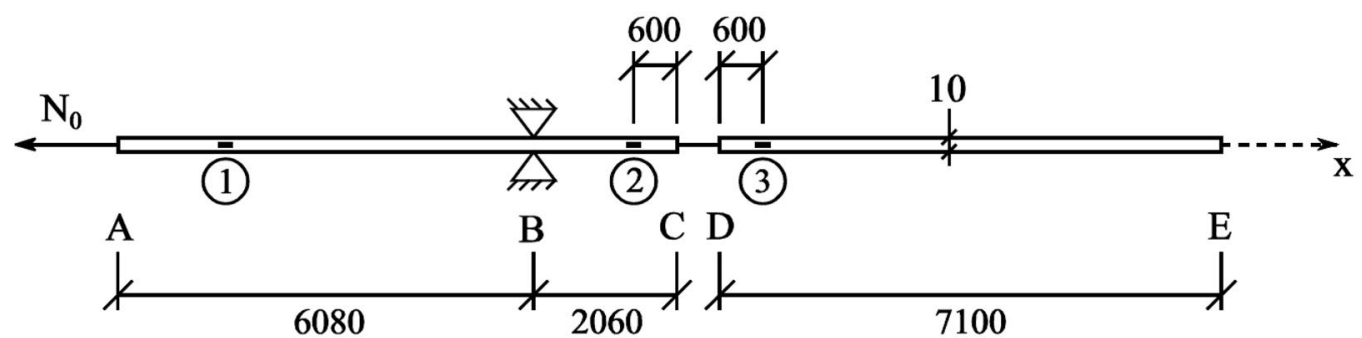

(b)

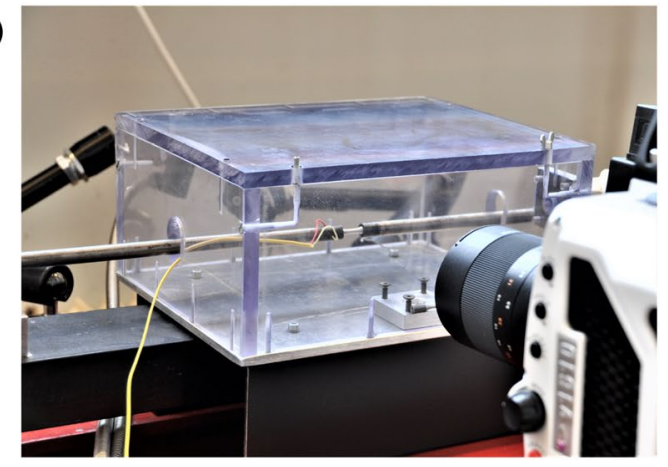

(c)

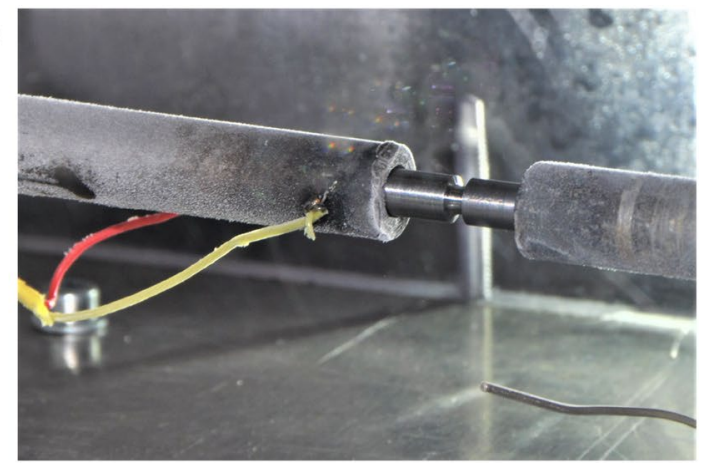

Fig. 4 Experimental set-up of the dynamic tensile tests. a Schematic view of the SHTB (dimensions in mm). b Polycarbonate temperature chamber. c Specimen located in testing position. Thermocouples attached to the bars to control the sub-zero temperature 


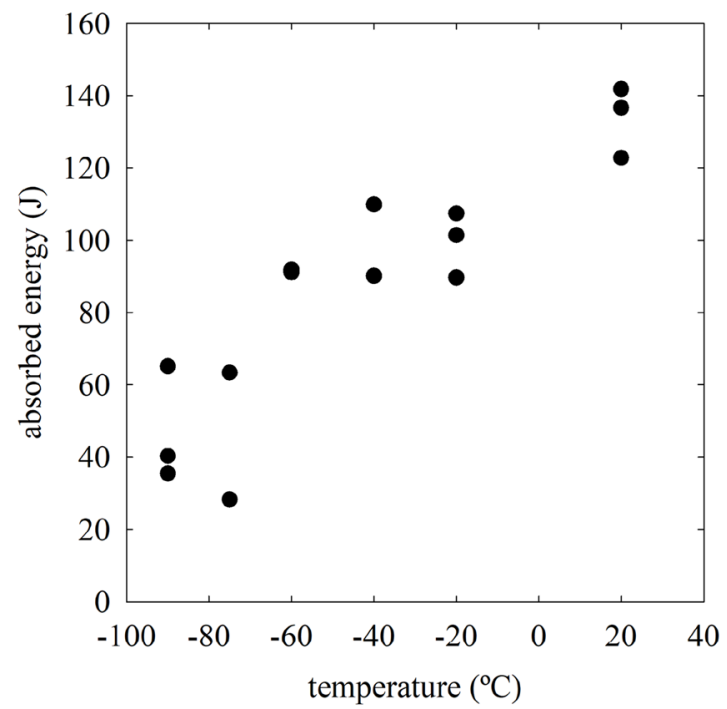

(a)

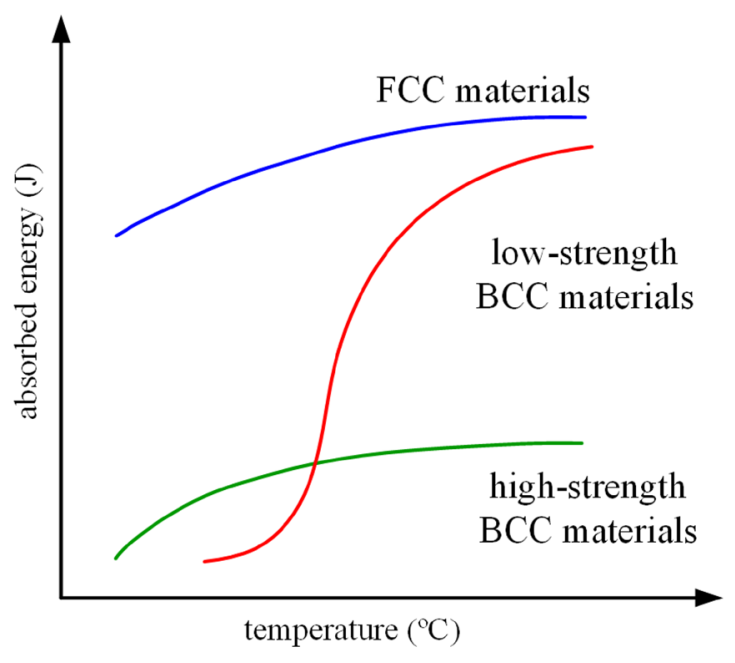

(b)

Fig. 5 Charpy V-notch tests: a The absorbed energy as a function of temperature, from $+20{ }^{\circ} \mathrm{C}$ down to $-90{ }^{\circ} \mathrm{C}$. $\mathbf{b}$ Illustration of the theoretical temperature-transition curve for different materials, adapted from Dieter [9]

revealed that the absorbed energy gradually decreased with decreasing temperature. However, contrary to what one would expect to observe in a typical steel with a DBTT, no clear drop in energy absorption at a specific temperature could be identified. According to Dieter [9], the shape of the temperature-transition curve highly depends on the material (see Fig. 5b). FCC and most HCP materials have such high notch toughness that brittle fracture is normally not a problem. On the contrary, BCC materials (such as steels) have much lower notch toughness. Thus, brittle fracture is in principle possible at all temperatures and strain rates. The notch toughness of low- and medium-strength BCC materials is strongly dependent on the temperature. At low temperature, fracture occurs by cleavage while at high temperature the fracture occurs by ductile rupture, and the temperature-transition curve may be abrupt. Furthermore, important changes in the transition temperature can be produced by changes in the chemical composition or the microstructure of mild steels. For high-strength steels, such as the Strenx 960 Plus investigated here, the transition temperature is as seen less distinct.

\section{Quasi-Static Tensile Tests}

In the quasi-static tensile tests, the force $F$ was measured by the calibrated load cell, while the minimum cross-section diameters of the specimen in two perpendicular directions, denoted $D_{1}$ and $D_{2}$, were provided using edge tracing (see "Experimental Procedures" section). As these test specimens were axisymmetric (see Fig. 1), the initial and current cross-section areas were calculated from $A_{0}=\frac{\pi}{4} D_{0}^{2}$ and $A=\frac{\pi}{4} D_{1} D_{2}$, respectively, where $D_{0}$ is the initial diameter of the specimen. The true stress $\sigma$ and the logarithmic strain $\varepsilon$ were then calculated as

$\sigma=\frac{F}{A}, \quad \varepsilon=\ln \left(\frac{A_{0}}{A}\right)$

Note that the true stress and logarithmic strain are average values over the minimum cross-section of the specimen after diffuse necking, and that plastic incompressibility and small elastic strains were assumed to obtain the logarithmic strain.

Obtained true stress-strain curves corresponding to the smooth specimens extracted from three different orientations $\left(0^{\circ}, 45^{\circ}\right.$ and $90^{\circ}$ with respect to the rolling direction) and tested at room temperature are shown in Fig. 6 a. These experimental results confirm that the stress-strain response is rather isotropic, even though minor differences in both flow stress and strain to failure are seen between the different specimen orientations.

Figure $6 \mathrm{~b}$ shows true stress-strain curves of smooth and pre-notched specimens extracted from the rolling direction and tested at both $+20{ }^{\circ} \mathrm{C}$ and $-40{ }^{\circ} \mathrm{C}$. The results revealed that for all the specimen geometries the flow stress increased with decreasing temperature, while the failure strain remained almost the same. Similar results on a $420 \mathrm{MPa}$ structural steel were found by Tu et al. [14], where the fracture strain did not deteriorate when the temperature decreased from room temperature down to $-60{ }^{\circ} \mathrm{C}$. 


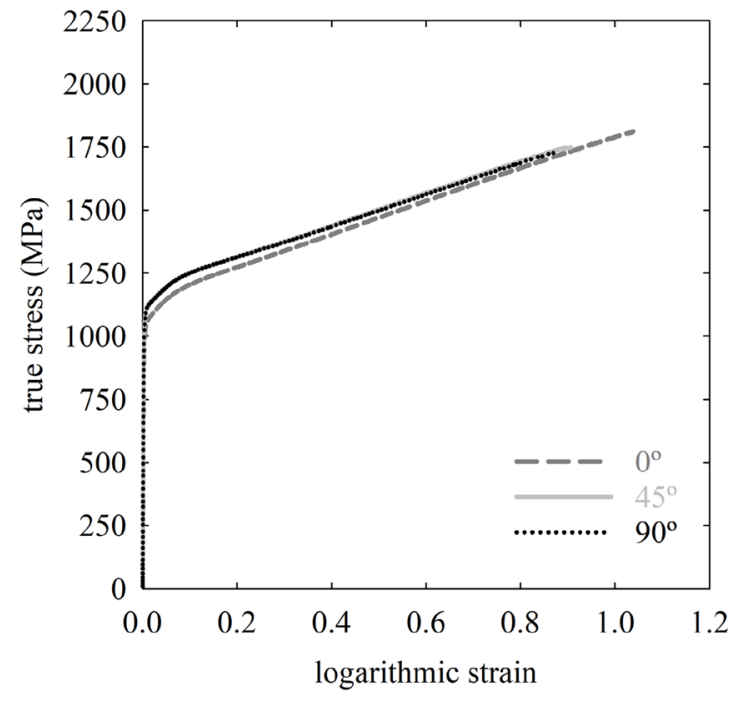

(a)

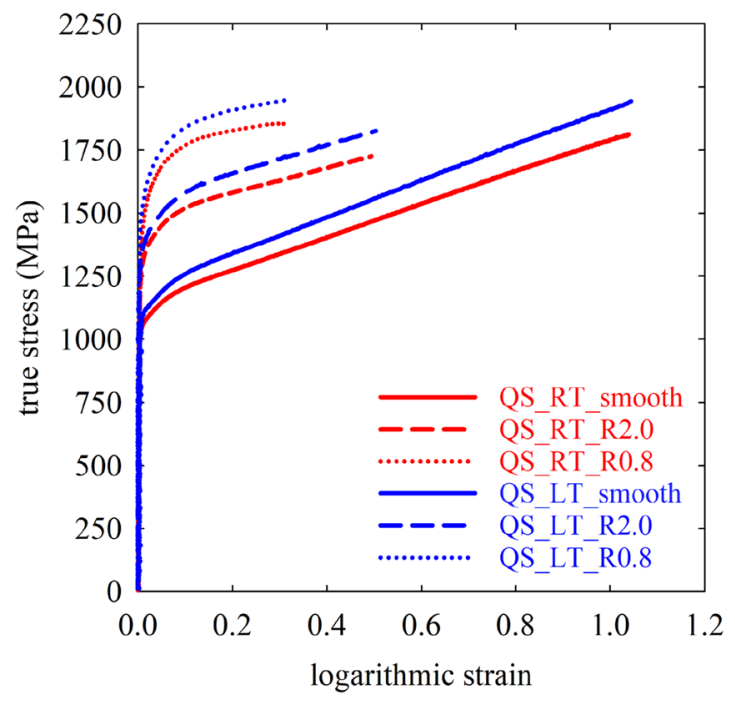

(b)

Fig. 6 True stress-strain curves of quasi-static tests: a Smooth specimens extracted from $0^{\circ}, 45^{\circ}$ and $90^{\circ}$ orientations at room temperature. $\mathbf{b}$ Smooth and pre-notched specimens from $0^{\circ}$ orientation at $+20^{\circ} \mathrm{C}$ (in red, RT) and $-40^{\circ} \mathrm{C}$ (in blue, LT) (Color figure online)

\section{Dynamic Tensile Tests}

The initial strain rate in the dynamic tensile tests of smooth specimens was between 100 and $1000 \mathrm{~s}^{-1}$, and the strain rate increased significantly after necking. Due to the initial notch, the strain rate in the pre-notched specimen tests was never constant. Since there was no apparent relationship between flow stress and strain rate, and since the variation of strain rate was less than an order of magnitude, all the dynamic tensile tests were treated as a single data set.

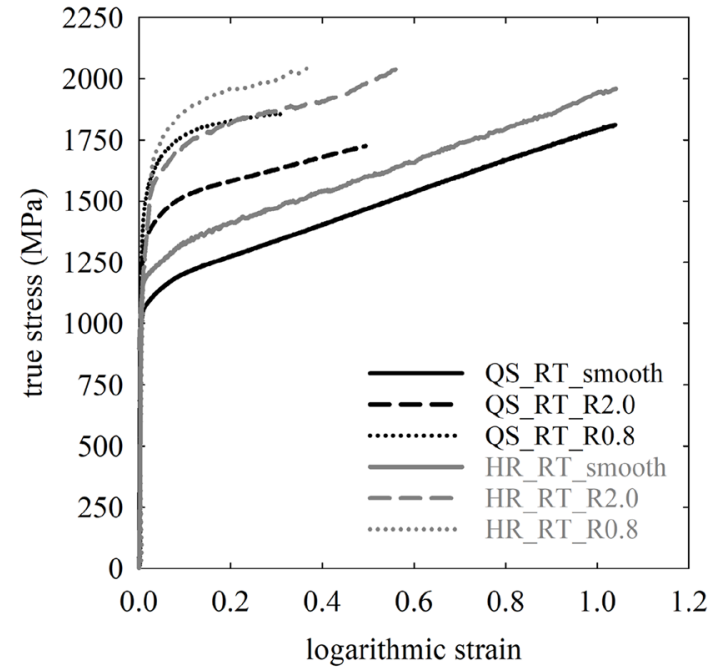

(a)
As it can be seen in Fig. 7a, the stress level increased with increasing strain rate, being slightly higher at low temperature, i.e., $-40{ }^{\circ} \mathrm{C}$, than at room temperature (see Fig. 7b). The Strenx 960 Plus exhibited positive strain rate sensitivity, which was roughly the same at room temperature and low temperature. It should be noted that, although two or three repetitions within each test series were performed, only a representative stress-strain curve for each geometry is shown in Figs. 6 and 7.

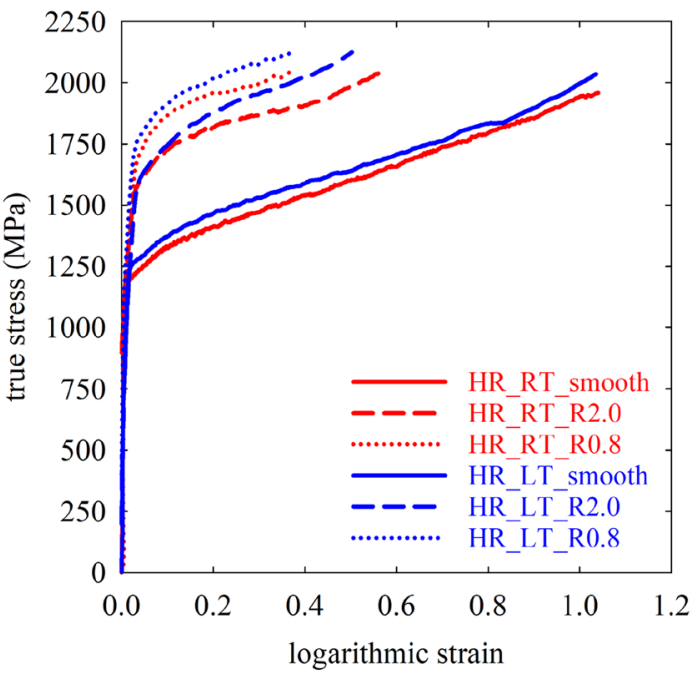

(b)

Fig. 7 a True stress-strain curves of both quasi-static (LR) and dynamic (HR) tensile tests at room temperature. b Effect of temperature on the dynamic tensile test, $+20^{\circ} \mathrm{C}$ (in red, RT) and $-40{ }^{\circ} \mathrm{C}$ (in blue, LT) (Color figure online) 


\section{Fractographic Study}

A fracture surface topography analysis was performed on some representative specimens to study the fracture mechanisms. The fracture surfaces were examined with a Zeiss Gemini SUPRA 55 VP FESEM. A first microstructural analysis of the material revealed a pure martensitic structure of the Strenx 960 Plus with a grain size of approximately $10-20 \mu \mathrm{m}$.

Cleavage fracture is typically represented by a multifaceted surface and 'river patterns' on each facet of the Charpy specimen [10]. None of these characteristics were observed on the fracture surfaces resulting from the Charpy tests. A clear dimple structure was seen on the fracture surface of the Charpy V-notch specimens; although delamination was more prominent at lower temperatures, as can be observed in Fig. 8. It is believed that the higher stress level in the material at $-40{ }^{\circ} \mathrm{C}$ is the main contributing factor to the greater tendency of delamination.

A classic dimple structure was observed on the tension specimen surfaces at all temperatures, indicating ductile failure. More shallow dimples could be observed on the fracture surface of pre-notched tension specimens (see Fig. 9), indicating less ductile behaviour. This effect was experimentally confirmed and could be observed in Fig. 6b, where the strain to failure decreased while the stress triaxiality increased because of the introduction of the notch.

As it can be seen in Fig. 10, dimples were shallower with decreasing temperature. One may assume that shallow dimples imply less ductile material behaviour. However, a reduction of strain to failure due to decreasing temperature could not be experimentally observed in Fig. 6 b. The shallower dimples observed at $-40{ }^{\circ} \mathrm{C}$ could be a delayed void formation due to low temperatures.

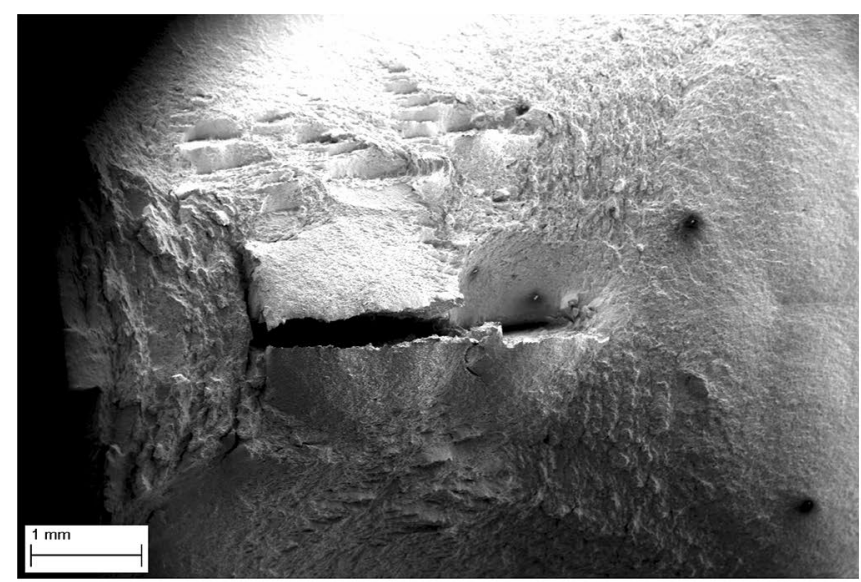

(a)

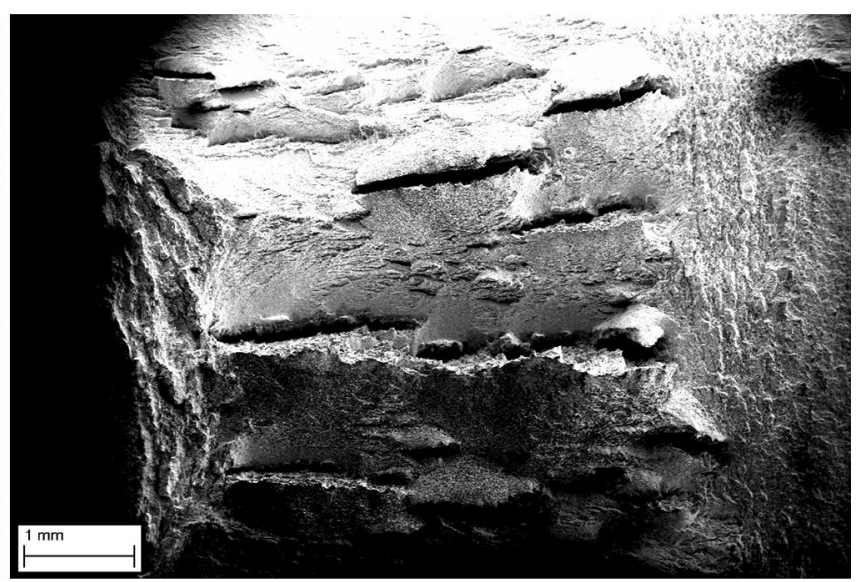

(b)

Fig. 8 Charpy V-notch specimens: a room temperature test. $\mathbf{b}-40{ }^{\circ} \mathrm{C}$ test

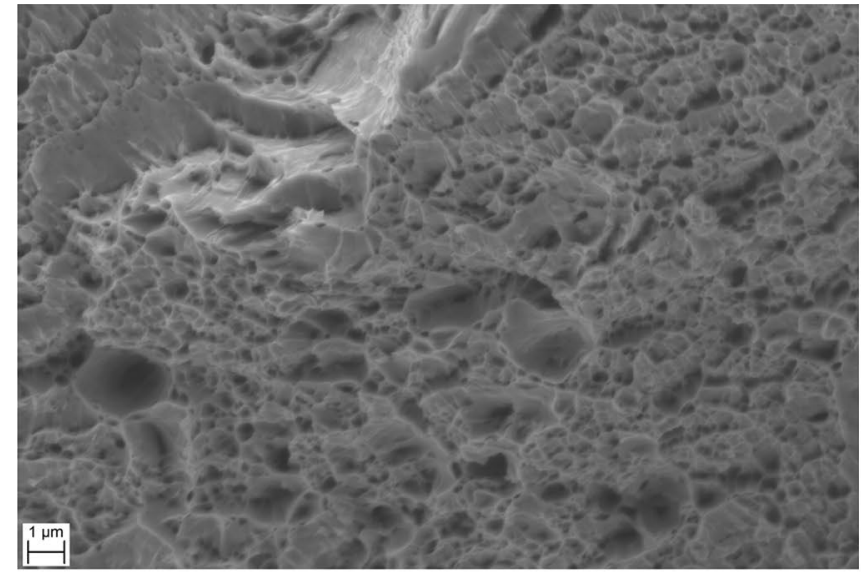

(a)

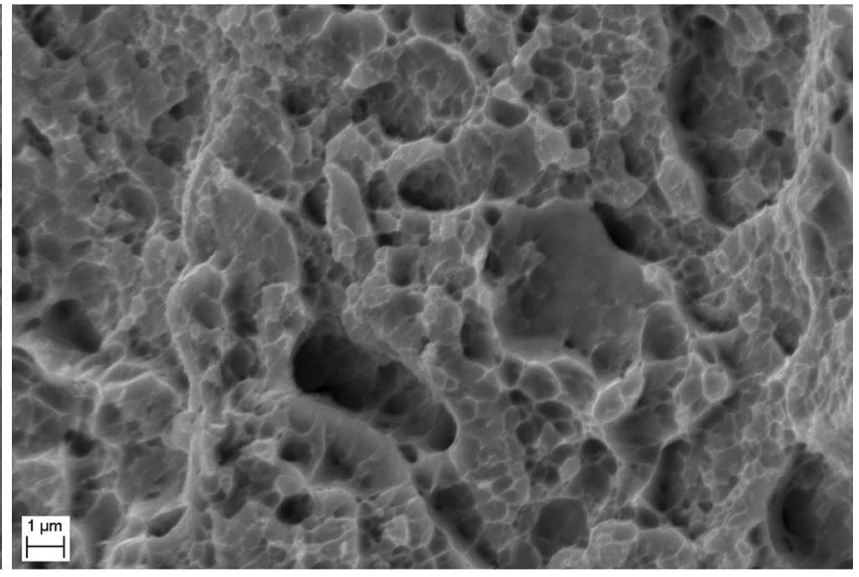

(b)

Fig. 9 Tension specimens from $0^{\circ}$ direction tested at room temperature. a Smooth. b Pre-notched with R0.8 


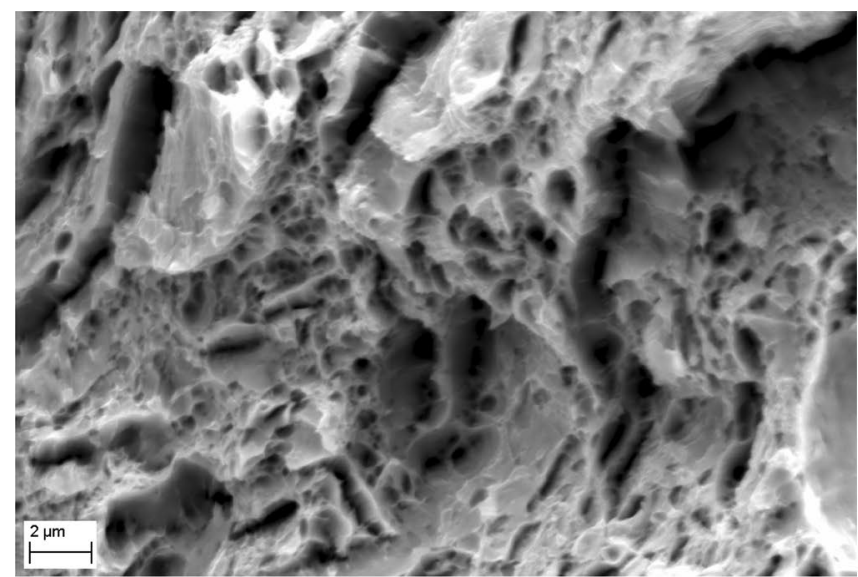

(a)

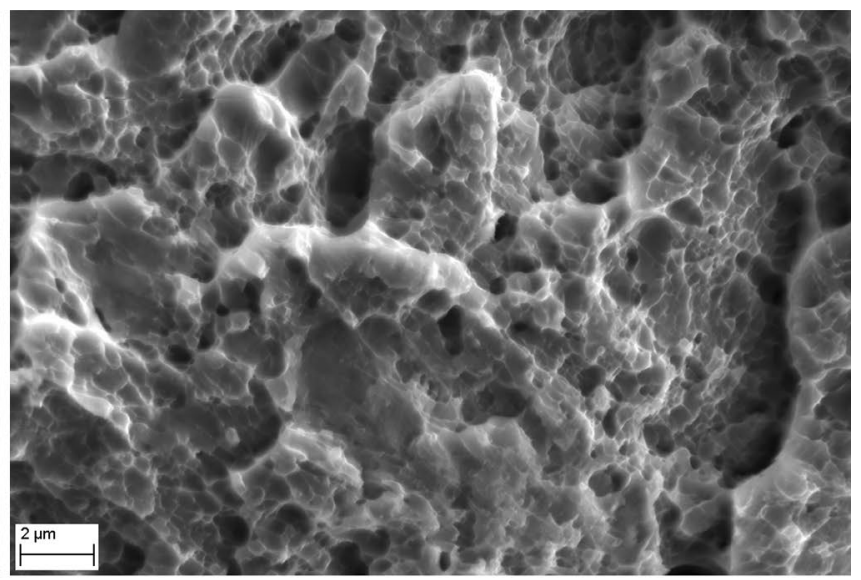

(b)

Fig. 10 Tension specimens from $0^{\circ}$ direction tested at $-40^{\circ} \mathrm{C}$. a Smooth. b Pre-notched with R0.8

Delamination was observed on all the specimens tested at both room temperature and $-40{ }^{\circ} \mathrm{C}$. It can be seen as the cracks, which are perpendicular to the thickness direction of the smooth tension specimen in Fig. 11a. Also, a large crack perpendicular to the thickness direction was observed in the centre of the notched specimens (see Fig. 11b). Similar cracks were observed by Manes et al. [21] on a pipeline steel. A possible reason they found was the relatively large tensile stresses induced by the strong necking in the thickness direction that lead to secondary cracks along the rolling plane of the material.

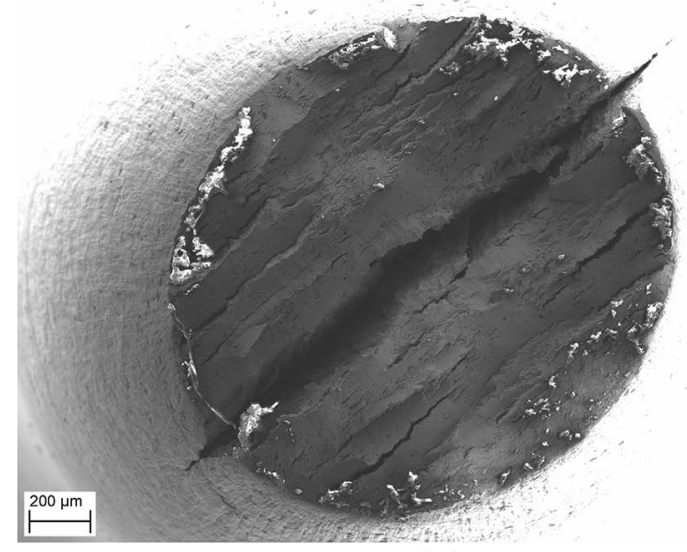

(a)

\section{Conclusions}

This experimental study showed that Strenx 960 Plus highstrength structural steel retained its ductility at temperatures as low as $-40^{\circ} \mathrm{C}$. Fractography revealed only dimple dominated ductile failure, thus brittle failure was not observed in any of the tests, not even in tests with combined high strain rate, high stress triaxiality and low temperature. The strain rate sensitivity was positive at room temperature as well as at sub-zero temperatures. This high-strength structural steel may therefore be a suitable material for use in protective structures in Arctic environments. However, it remains to check if an evoked fatigue crack, created to significantly increase the stress triaxiality at the crack tip, will alter this conclusion.

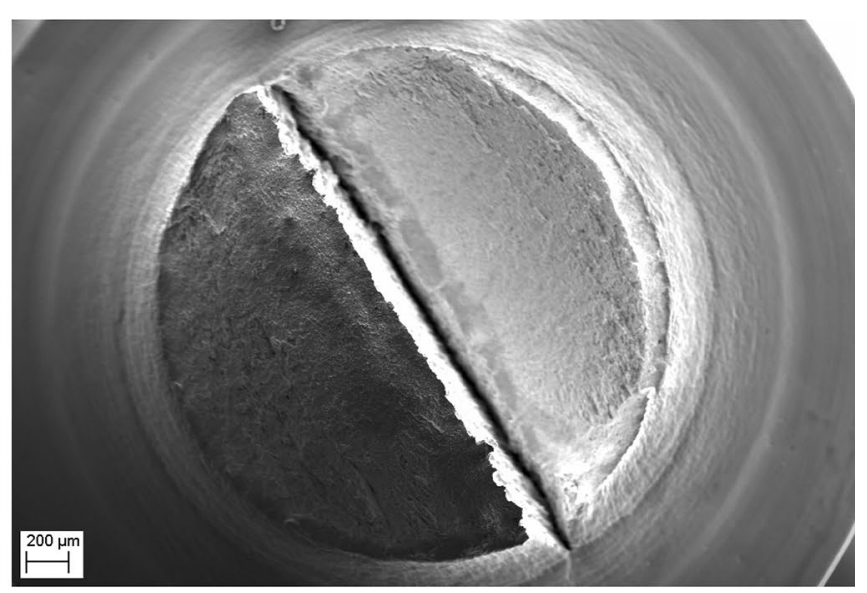

(b)

Fig. 11 Tension specimens from $0^{\circ}$ direction tested at room temperature. a Smooth. b Pre-notched with R0.8 
Acknowledgements The present work has been carried out with the financial support from Centre for Advanced Structural Analysis (CASA) through the Research Council of Norway's Centre for Research based Innovation (CRI) scheme (Project 237885). Thankful acknowledgements are made to Tore A. Kristensen at SINTEF Industry and Trond Auestad at Department of Structural Engineering, NTNU, for assistance with the various experimental programmes.

Open Access This article is licensed under a Creative Commons Attribution 4.0 International License, which permits use, sharing, adaptation, distribution and reproduction in any medium or format, as long as you give appropriate credit to the original author(s) and the source, provide a link to the Creative Commons licence, and indicate if changes were made. The images or other third party material in this article are included in the article's Creative Commons licence, unless indicated otherwise in a credit line to the material. If material is not included in the article's Creative Commons licence and your intended use is not permitted by statutory regulation or exceeds the permitted use, you will need to obtain permission directly from the copyright holder. To view a copy of this licence, visit http://creativecommons.org/licenses/by/4.0/.

\section{References}

1. Ehlers S, Østby E (2012) Increased crashworthiness due to arctic conditions - the influence of sub-zero temperature. Mar Struct 28(1):86-100

2. Layus P, Kah P, Ryabov V, Martikainen J (2016) Evaluation of applicability of thick E500 TMCP and F500 W QT steel plates for Arctic service. Int J Mech Mater Eng 11(1):4

3. Nam W, Amdahl J, Hopperstad OS (2016) Influence of brittle fracture on the crashworthiness of ship and offshore structures in Arctic conditions. In: 7th international conference on collision and grounding of ships and offshore structures (ICCGS 2016)

4. Paik JK, Kim BJ, Park DK, Jang BS (2011) On quasi-static crushing of thin-walled steel structures in cold temperature: experimental and numerical studies. Int J Impact Eng 38(1):13-28

5. Park DK, Kim KJ, Lee JH, Jung BG, Han X, Kim BJ, Seo JK, Ha YC, Paik JK, Matsumoto T, Byeon SH, Kim MS (2015) Collision tests on steel-plated structures in low temperature. In: ASME 2015 - 34th international conference on ocean, offshore and arctic engineering

6. Valtonen K, Ratia V, Ramakrishnan KR, Apostol M, Terva J, Kuokkala V-T (2019) Impact wear and mechanical behavior of steels at subzero temperatures. Tribol Int 129:476-493
7. Xie J, Zhao X, Yan J-B (2018) Mechanical properties of high strength steel strand at low temperatures: tests and analysis. Constr Build Mater 189:1076-1092

8. Xie J, Zhu G-R, Yan J-B (2018) Mechanical properties of headed studs at low temperatures in Arctic infrastructure. J Constr Steel Res 149:130-140

9. Dieter GE (1986) Mechanical metallurgy, 3rd edn. Mc Graw-Hill Book Co., New York

10. Anderson TL (2005) Fracture mechanics: fundamentals and applications. CRC Press, Boca Raton

11. Meyers MA, Chawla KK (2008) Mechanical behavior of materials, 2nd edn. Cambridge University Press, Cambridge

12. Vilamosa V, Clausen AH, Fagerholt E, Hopperstad OS, Børvik T (2014) Local measurement of stress-strain behaviour of ductile materials at elevated temperatures in a split-Hopkinson tension bar system. Strain 50(3):223-235

13. Erice B, Gálvez F, Cendón DA, Sánchez-Gálvez V (2012) Flow and fracture behaviour of FV535 steel at different triaxialities, strain rates and temperatures. Eng Fract Mech 79:1-17

14. Tu S, Ren X, Kristensen TA, He J, Zhang Z (2018) Study of lowtemperature effect on the fracture locus of a 420-MPa structural steel with the edge tracing method. Fatigue Fract Eng Mater Struct 41(8):1649-1661

15. ISO (2016) Metallic materials-Charpy pendulum impact testpart 1: test method, ISO 148-1

16. ISO (2016) Metallic materials-Charpy pendulum impact testpart 2: Verification of testing machines, ISO 148-2

17. Fagerholt E (2012) Field measurements in mechanical testing using close-range photogrammetry and digital image analysis. NTNU, Trondheim

18. Thomesen S, Hopperstad OS, Børvik T (2018) On the material characterization of an aluminium alloy using different specimens and identification. Methods 2(8):400

19. User Manual-eCorr-Digital Image Correlation tool. https:// www.ntnu.edu/kt/ecorr, 2019

20. Chen Y, Clausen AH, Hopperstad OS, Langseth M (2011) Application of a split-Hopkinson tension bar in a mutual assessment of experimental tests and numerical predictions. Int J Impact Eng 38(10):824-836

21. Manes A, Porcaro R, Ilstad H, Levold E, Langseth M, Børvik $\mathrm{T}$ (2012) The behaviour of an offshore steel pipeline material subjected to bending and stretching. Ships Offshore Struct 7(4):371-387

Publisher's Note Springer Nature remains neutral with regard to jurisdictional claims in published maps and institutional affiliations. 